\section{Zeckenprotein bekämpft Asthma}

\author{
Histamin ist als Mediator der allergischen Entzündung auch an der \\ Pathophysiologie des Asthma bronchiale beteiligt. H1-Blocker haben \\ sich zur Asthmatherapie wegen zu schwacher Wirkung nicht durch- \\ gesetzt. Einen zur Rezeptorblockade alternativen Therapieansatz \\ bietet die Neutralisation freigesetzten Histamins.
}

$\mathrm{H}$ istamin induziert bei Patienten mit allergischem Asthma die Kontraktion und Hyperplasie der glatten Atemwegsmuskulatur und fördert Schleimproduktion, Plamaexsudation sowie Vasodilatation. Vermittelt werden die Effekte primär über die Histaminrezeptoren $\mathrm{H} 1$ und $\mathrm{H} 4$. Vermindert werden kann die Wirkung von Histamin durch die Blockade der Rezeptoren - z. B. durch H1-Blocker - oder aber durch Absättigung der Rezeptor-Bindungsstellen des Histaminmoleküls selbst. Letzteres gelingt offenbar mit EV131, einem Histamin-bindenden Protein aus der Zecke Rhipicephalus appendiculatus.

In einem Mausmodell, bei dem bei gegen Ovalbumin sensibilisierten Mäusen durch Antigenprovokation den

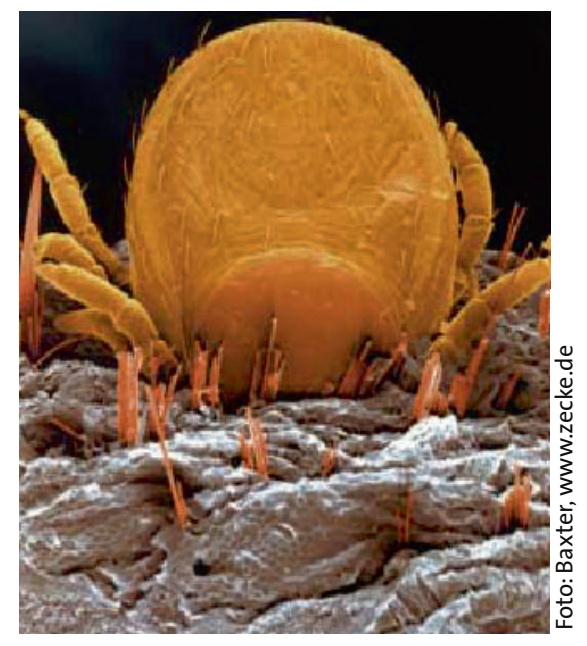

Zecken geben während des Saugvorgangs Histamin-bindende Proteine an den Wirt ab. menschlichen Asthmasymptomen ähnliche Reaktionen ausgelöst werden, wurde EV131 getestet. Tatsächlich reduzierte die intranasale Gabe des Poteins die Atemwegshyperreagibilität um $70 \%$ und verhinderte die peribronchiale Entzündung, die pulmonale Eosinophilie, die Hypersekretion von Schleim und die Freisetzung von IL-4 und IL-5. Der inhibitorische Effekt von EV131 auf die bronchiale Hyperreaktivität war vergleichbar mit dem von Glukokortikoiden. Wurden die Histaminbindungstellen des Proteins vor der Applikation abgesättigt, blieb das Molekül wirkungslos.

Fazit: Das aus Zecken isolierte Protein EV131 bindet das bei allergischen Reaktionen freigesetzte Histamin und verhindert dessen Effekte an den Histaminrezeptoren der Atemwege. Dadurch können im Asthma-Mausmodell bronchiale Hyperreaktivität und Entzündungsreaktion unterdrückt weren.

Couillin I et al. Arthropod-derived histamine-binding protein prevents murine allergic asthma. J Immunol 2004; 173: $3281-6$

\section{Geht Asthmaprävention auch sublingual?}

\begin{abstract}
Die klassische subkutane spezifische Immuntherapie (SIT) kann die Entwicklung eines Asthmas bei Kindern mit allergischer Rhinitis verhindern. Für die sublinguale Immuntherapie (SLIT) stand der Nachweis eines Präventiveffekts bisher noch aus. Eine offene Studie gibt jetzt erste Hinweise auf eine Asthmaschutzwirkung auch durch SLIT.
\end{abstract}

\footnotetext{
A n sechs italienischen Studienzentren erhielten 113 Kinder mit einer Gräserpollenallergie und Rhinokonjunktivitis 3 Jahre während der Pollenflugsaison eine SLIT oder lediglich eine Bedarfsmedikation mit Cetirizin, Loratadin, nasalem Budesonid oder Salbutamol. Zur SLIT wurden nach einer 15tägigen Auftitrationsphase fünf Tropfen einer Konzentration von $25 \mathrm{BU} / \mathrm{ml}$ entsprechend $0,5 \mu \mathrm{g}$ Major-Gräserpollenallergene - an 5 Tagen der Woche für jeweils 2 Minuten unter der Zunge appliziert. Die Bedarfsmedikation sowie Symptome der Rhinokonjunktivitis und
}

eines möglicherweise neu hinzu gekommenen Asthmas (wiederholt auftretender Husten, Atemprobleme) wurden von den Kinder bzw. deren Eltern in einem Tagebuch notiert und anschließend quantifiziert.

Im 2. und 3. Behandlungsjahr benötigten die Kinder der aktiven Therapiegruppe weniger Bedarfsmedikamente als die Kontrollgruppe, der Symptomscore für die Rhinokonjunktivitis war geringfügig erniedrigt. Am Ende der 3jährigen Therapie hatten die Kinder der Kontrollgruppe 3,8mal häufiger Asthma entwickelt als die mit SLIT behandelten
Kinder (95\%-Konfidenzintervall 1,510,0). 16 Kinder beendeten die Studie vorzeitig, keines aber aufgrund von $\mathrm{Ne}-$ benwirkungen. Unter der aktiven Behandlung kam es in zwei Fällen während der Auftitrationsphase und in einem Fall während der Erhaltungphase zu leichten Nebenwirkungen.

Fazit: Die Ergebnisse dieser offen durchgeführten Studie mit selbst berichteten Symptomen geben zwar möglicherweise ein leicht verzerrtes Bild zugunsten der aktiven Medikation wieder, trotzdem weisen sie darauf hin, dass eine während der Pollenflugsaison durchgeführte SLIT das Neuauftreten eines Asthmas bei Kindern mit allergischer Rhinitis verhindern kann. $\quad b k$

Novembre E et al. Coseasonal sublingual immunotherapy reduces the development of asthma in children with allergic rhinoconjunctivitis. J Allergy Clin Immunol 2004; 114: 851-7 